\title{
El CONTROL ADUANERO EN El ECUADOR, UNA VISIÓN AL PERÍODO 2013 - 2016
}

\author{
THE CUSTOMS CONTROL IN ECUADOR, \\ A VISION TO THE PERIOD 2013 - 2016
}

\author{
LAURA ANGÉLICA DE LA CRUZ GUERRERO \\ Universidad Tecnológica Equinoccial \\ Correo electrónico: laura.delacruz@ute.edu.ec \\ DARWIN EUGENIO ROSALES NIETO \\ Universidad Tecnológica Equinoccial \\ Correo electrónico:darwin.rosales@ute.edu.ec
}

FECHA DE RECEPCIÓN: 07/11/2016

FECHA DE ACEPTACIÓN: 16/12/2016

\begin{abstract}
RESUMEN
El Ecuador tiene como principales fuentes de financiamiento de su presupuesto los ingresos provenientes de las exportaciones, especialmente de las ventas del petróleo y sus derivados; el financiamiento internacional y la recaudación tributaria. De esta última, un componente importante es la recaudación aduanera, cuyos mayores rubros corresponden a impuestos Ad Valorem, Impuestos a Consumos Especiales, Salvaguardias e Impuesto al Valor Agregado. De ahí la razón para que el Servicio Nacional de Aduana despliegue estrategias y planes que le permitan asegurar un adecuado control aduanero. La normativa internacional comprende una serie de conceptos que facilitan la ejecución de operaciones tanto al interior del país, como en cooperación con las Administraciones Aduaneras de otros Estados. El Ecuador ha emprendido un proceso de modernización del Sistema Aduanero, el mismo que ha incluido reformas legales, equipamiento tecnológico, optimización y desarrollo del talento humano, desarrollo e implementación de procesos y procedimientos; todo ello ha generado un incremento de las recaudaciones, reducción de tiempos de despacho, eficiencia en patrullajes terrestres y marítimos y un gran despliegue del control posterior, entre otros aspectos.
\end{abstract}

Palabras clave: Control aduanero, Gestión de riesgo.

\begin{abstract}
Ecuador has, as main sources of financing of its budget, the revenues from exports, especially from sales of oil and its derivatives; international financing and tax collection. Of this last one, an important component is the customs collection, whose major items correspond to Ad valorem taxes, Taxes to Special Consumers, Safeguards and Value Added Tax. Hence the reason for the National Customs Service to deploy strategies and plans that allow them to ensure adequate customs control. The international regulations include a series of concepts that facilitate the execution of operations, both within the country and in cooperation with the Customs Administrations of other States. Ecuador has undertaken a process of modernization of the Customs System, which has included legal reforms, technological equipment, optimization and development of human talent, development and implementation of processes and procedures; all of which has led to an increase in revenues, reduction of dispatch times, efficiency in land and sea patrols, and a large deployment of subsequent control, among other aspects.
\end{abstract}

Keywords: Custom control, Risk control. 


\section{Introducción}

El comercio internacional a lo largo de la historia ha pasado por varias etapas en la búsqueda de un organismo que lo regule y que, al ser aceptado por los países actores, garantice tranparencia y equidad en sus acciones.

Si se remite a las primeras décadas del siglo pasado miramos que el colapso del comercio producido en los ańos treinta generó varias iniciativas, entre ellas la conformación de la Organización Internacional de Comercio -OIC (International Trade Organization -ITO), que nació como parte de la Carta de La Habana y que finalmente, ante la no aprobación del Congreso de los Estados Unidos, tuvo que descartársela, dando paso al GATT (General Agreement on Tariffs and Trade) Acuerdo General sobre Aranceles Aduaneros y Comercio, cuya vigencia a partir de 1947 generó una paulatina liberación del comercio multilateral, al tener como base de su accionar, primero, la cláusula de la "nación más favorecida", a la que le asigna tal importancia que se encuentra inscrita en su primer artículo, y luego, la cláusula de la "reciprocidad de convenios". En ese contexto, el GATT estableció las reglas bajo las cuales se desarrolló gran parte del comercio mundial hasta la década de los ochenta en que empieza a configurarse nuevas formas de organización de los países, dando paso a estructuras regionales muy poderosas como la Comunidad Económica Europea (actual Unión Europea) y a inicios de los noventa del Tratado de Libre Comercio de América del Norte -TLCAN o NAFTA por sus siglas en inglés.

Es entonces que aparece la Organización Mundial de Comercio, OMC, y asume como uno de sus roles principales evitar las desviaciones del comercio por parte de los bloques regionales, servir de foro para la negociación de acuerdos encaminados a reducir los obstáculos al comercio internacional y a asegurar condiciones de igualdad para todos los miembros. En ese sentido, se amplía la concepción de Política Comercial que hasta ese entonces se limitaba a cuestiones arancelarias y a medidas que regulaban el paso de mercancías por las fronteras, fijar cuotas o contingentes, regulando, permitiendo o prohibiendo tales o cuales transacciones, dando también un giro al concepto de comercio exterior como el movimiento transfronterizo de los factores de la producción, es decir no solo de mercancías, sino tambien de personas, de servicios y de capital; hoy la Política Comercial abarca nuevos aspectos que van más allá de las

...cuestiones clásicas como la creación de empleo y las políticas agrícolas e industriales, junto con las políticas de desarrollo y la política exterior y cuestiones más nuevas como los derechos laborales y la política ambiental, sino también (entre otras cosas) la promoción del imperio de la ley, la responsabilidad social de las empresas, la protección de los intereses y derechos del consumidor e incluso las políticas de vecindad. (CRAIG, 2013, pág. xi)

Es en ese entorno que a partir del 21 de diciembre de 1995 el Ecuador decide adherirse como miembro pleno de la Organización Mundial de Comercio creada el 27 de septiembre de 1995, según Acuerdo firmado en Ginebra, Suiza; a partir de ese momento su política comercial debe inscribierse en

...los principios fundamentales y rectores de la OMC, es decir: la apertura de las fronteras, la garantía del principio de la nación más favorecida y del trato no discriminatorio entre los Miembros, así como el compromiso de lograr la transparencia en sus actividades, ....esa apertura de los mercados debe ir acompañada de políticas nacionales e internacionales racionales que contribuyan al crecimiento económico y al desarrollo en consonancia con las necesidades y aspiraciones de cada uno de los Miembros. (OMC, 2014)

La Comunidad Andina - CAN, en la decisión 574, define la expresión "control aduanero" como "el conjunto de medidas adoptadas por la administración aduanera con el objeto de asegurar el cumplimiento de la legislación aduanera o de otras disposiciones cuya aplicación o ejecución es de competencia o responsabilidad de las aduanas" (CAN 1, 2003, pág. 4). Nótese que las dos organizaciones incluyen en las obligaciones de la Aduana no solo a las disposiciones por ella emitidas, sino 
a todas aquellas que expida cualquier autoridad $\mathrm{u}$ organismo, de cuyo cumplimiento sea responsable o esté bajo la potestad de la Aduana.

En el Ecuador, la norma legal que regula las relaciones jurídicas entre el Estado y las personas naturales o jurídicas que realizan actividades directa $\mathrm{o}$ indirectamente relacionadas con el tráfico internacional de mercancías es el Código Orgánico de la Producción, Comercio e Inversiones, COPCI, libro V, cuyo reglamento en su artículo dos define al Control Aduanero como "el conjunto de medidas adoptadas por la Autoridad Aduanera con el objeto de asegurar el cumplimiento de la legislación, cuya aplicación o ejecución es de su competencia o responsabilidad, al cual deberán someterse los distintos operadores de comercio exterior." (Asamblea Nacional 1, 2010, pág. 28)

\section{Metodología}

Se realizó un análisis exploratorio y descriptivo de información contenida en libros, revistas científicas, documentos emitidos por instituciones públicas, especialmente boletines e informes de gestión, de los cuales se obtuvieron estadísticas que fueron analizadas y contrastadas que permitieron un enfoque global y objetivo del tema estudiado.

El método inductivo - deductivo fue empleado para depurar la información recopilada, la misma que luego de su análisis permitió llegar a las conclusiones que quedan plasmadas en este estudio. Asimismo, se empleó el método histórico el cual favoreció para estudiar los diferentes procesos que se han llevado a cabo y los resultados de cada etapa, hasta llegar al momento actual, verificando su evolución y los avances del control aduanero en Ecuador.

\section{Resultados}

\section{Marco legal}

La normativa sobre Control Aduanero que rige para el Ecuador, recoge conceptos y mandatos de regulaciones que aplican el criterio de Suprana- cionalidad, entre ellas: Convenio de Kyoto, Anexo General Capítulo 6- Directivas sobre Control Aduanero Decisión 574, CAN- Régimen Andino sobre Control Aduanero Decisión 571, CANValor en Aduana de las mercancías importadas También está la norma interna contenida en el Libro V del COPCI y en el Reglamento al Título de la Facilitación Aduanera para el Comercio, además de Manuales, Boletines y Resoluciones emitidas por el SENAE sobre las actividades que deben cumplir los funcionarios, Operadores de Comercio Exterior y las personas naturales y jurídicas involucradas, de tal manera que se garantice un despacho ágil sin que ello signifique sacrificar el control estatal ejercido a través de la Aduana.

En un resumen del contenido de las citadas normas legales (OMA 1, 2013) podríamos decir que presentan detalladamente las mejores prácticas y otros asuntos que toda administración aduanera moderna que ejecute un programa de control aduanero, debería tener en cuenta, procurando un equilibrio entre el control y la facilitación al comercio de mercancías, implementando procedimientos de control basados en la gestión de riesgos, los mismos que deben ser permanentemente revisados y ajustados.

La Decisión 574 (CAN 1, 2003) especifica que el control aduanero se aplicará al ingreso, permanencia, traslado, circulación, almacenamiento, y salida de mercancías, unidades de carga y medios de transporte, hacia y desde el territorio aduanero comunitario. Asimismo, el control aduanero se ejercerá sobre las personas que intervienen en las operaciones de comercio exterior y sobre las que entren o salgan del territorio aduanero. Para ello establece que el control aduanero podrá realizarse en las fases siguientes:

a) Control anterior, el ejercido por la administración aduanera antes de la admisión de la declaración aduanera de mercancías. Es decir cuando los operadores de comercio exterior envían un documento físico o magnético permite a los funcionarios de aduana desarrollar análisis de riesgos apoyándose en herramientas informáticas u otros elementos que les guíen hacia la detección de posibles fraudes. 
Es importante que las mercancías estén sujetas a control y vigilancia mientras se encuentren a bordo del medio de transporte y durante el traslado al recinto autorizado.

b) Control durante el despacho, el ejercido desde el momento de la admisión de la declaración por la aduana y hasta el momento del levante o embarque de las mercancías. En esta etapa se debe considerar que cualquier actividad que incremente el tiempo de despacho causará molestias al usuario, por lo que es recomendable aplicar controles selectivos a determinadas Declaraciones Aduaneras Únicas, basados en criterios de gestión de riesgos, de acuerdo con los cuales se harán reconocimientos físicos o simplemente documentales. c) Control posterior, el ejercido a partir del levante o del embarque de las mercancías despachadas para un determinado régimen aduanero. Es recomendable que estos controles obedezcan a una planificación anual en la que se defina si se realizará un Control Documental Diferido que consiste en la revisión de declaraciones aduaneras presentadas en el despacho aduanero de las mercancías, o si se realizará una Auditoría que implica las revisiones documentarias y comerciales de las transacciones efectuadas por el operador de comercio, con la finalidad de verificar el cumplimiento de las obligaciones aduaneras. Esta facultad debe estar contemplada en los códigos tributarios nacionales y en la legislación aduanera de cada país.

Figura 1. Categorías del Control Aduanero

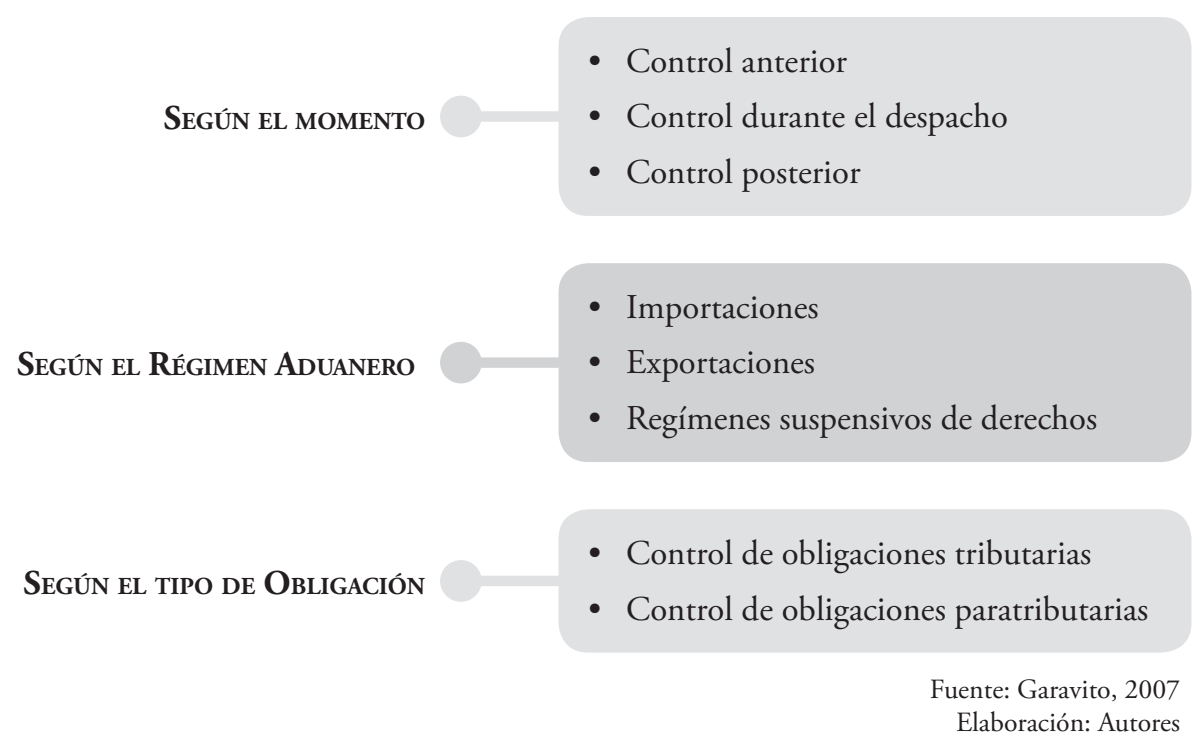

El Código Orgánico de la Producción, Comercio e Inversiones (Asamblea Nacional 1, 2010), le dedica el Capítulo V al tema del Control Aduanero, del que puntualiza se aplicará al ingreso, permanencia, traslado, circulación, almacenamiento y salida de mercancías, unidades de carga y medios de transporte hacia y desde el territorio nacional, inclusive la mercadería que entre y salga de las Zonas Especiales de Desarrollo Económico, por cualquier motivo. Señala que el control se hace extensivo a las personas que intervienen en las operaciones de comercio exterior y sobre las que entren y salgan del territorio aduanero.

En cuanto a las fases, contempla las mismas que las citadas en la normativa internacional, con la aclaración que el control posterior se lo podrá realizar dentro de cinco años contados desde la fecha de pago de los tributos al comercio exterior. Si se determina que la declaración adoleció de errores, que den lugar a diferencias a favor del sujeto activo, se procederá a la rectificación res- 
pectiva sin perjuicio de las demás acciones que legalmente correspondan, la rectificación de tributos en firme, será título ejecutivo y suficiente para ejercer la acción coactiva.

De considerarlo necesario el Servicio Nacional de Aduana del Ecuador podrá disponer la realización de auditorías a los regímenes especiales dentro de un plazo de cinco años contados a partir de la fecha de la declaración aduanera, para lo cual se podrá efectuar todo tipo de constataciones, sean estas documentales, contables o físicas.

Se establece también la posibilidad que la unidad operativa del Servicio Nacional de Aduana del Ecuador encargada del control posterior aprehenda mercancías y objetos que puedan constituir elementos de convicción o evidencia de la comisión de una infracción aduanera y ponerlas inmediatamente a disposición de los servidores a cargo de la dirección distrital que corresponda.

En el Reglamento al Título de la Facilitación Aduanera para el Comercio del libro V del COPCI (Asamblea Nacional 2, 2011), en el capítulo VI es claro al señalar que El Servicio Nacional de Aduana del Ecuador podrá efectuar el control posterior sin que se necesite una autorización judicial alguna para dicho fin, a cualquier operador de comercio exterior vinculado directa o indirectamente al tráfico internacional de mercancías objeto del control, y a cualquier otra persona que esté en posesión de mercancías, disponga de información, documentos o datos relativos a las operaciones sujetas al control aduanero. También podrá examinar y requerir información contable, operaciones bancarias, documentos, archivos, soportes magnéticos, datos informáticos y cualquier otra información relacionada con dichas mercancías.

Se establece que las Fuerzas Armadas y la Policía Nacional colaborarán con el Servicio Nacional de Aduana del Ecuador en el control fronterizo y en los distritos aduaneros de forma permanente con el fin de coadyuvar a evitar la comisión de los delitos tipificados en el Código Orgánico de la Producción, Comercio e Inversiones. También, cuando sea requerido, las fuerzas del orden público deberán apoyar al Servicio Nacional de
Aduana del Ecuador en la ejecución de operativos de control posterior u otras acciones propias de su administración.

Se contempla la Inmovilización de mercancías como una opción de la Aduana en zona primaria ante, la presunción de la comisión de un delito aduanero, a excepción de los casos en que la misma surja durante el acto de aforo, podrá autorizar la inspección de las mercancías con la presencia del propietario, consignatario o su representante de las mercancías; o, de ser el caso, al no ubicarlos o al no presentarse en la fecha establecida por la Autoridad Aduanera, realizará tal inspección de manera inmediata, bajo absoluta responsabilidad del propietario, consignatario o su representante dentro del tiempo establecido en el Código Orgánico de la Producción, Comercio e Inversiones. De confirmarse la presunción de la comisión de una infracción aduanera y si no se excediere de los montos previstos para que se configure el delito de defraudación, se procederá de acuerdo con el procedimiento establecido para el efecto por la Directora o el Director General del Servicio Nacional de Aduana del Ecuador y las mercancías objeto de infracción serán aprehendidas y permanecerán bajo la custodia del Servicio Nacional de Aduana del Ecuador hasta la culminación del proceso pertinente, esto es, que se hubieren cumplido todas las formalidades aduaneras que correspondan según los procedimientos que para el efecto establezca la Dirección General del Servicio Nacional de Aduana del Ecuador, satisfecho todos los tributos al comercio exterior y pagado o garantizada la multa respectiva.

En caso de que se determinare el cometimiento de una infracción aduanera tipificada como contravención o falta reglamentaria, se procederá de acuerdo con lo establecido para el efecto por la Dirección General, y las mercancías respectivas deberán ser entregadas una vez satisfechos los tributos al comercio exterior, sin perjuicio del procedimiento sancionatorio iniciado para tal efecto.

La devolución de las unidades de carga y/o medios de transporte en los casos en que se hubiere aplicado la inmovilización de mercancías, se efectuará siguiendo el procedimiento establecido 
para el efecto por la Directora o el Director General del Servicio Nacional de Aduana del Ecuador.

También se define la figura de la retención provisional que consiste en la toma de posesión forzosa de mercancías en zona secundaria o como producto de operativos de control posterior y su traslado hacia las bodegas aduaneras, $\mathrm{u}$ otro lugar designado para el efecto por la Autoridad Aduanera, mientras se determine la situación legal de la mercancía. La retención no podrá durar más de tres días hábiles, vencido este plazo se deberá continuar con el trámite respectivo. Si como resultado de las investigaciones o controles ejecutados por las unidades operativas del Servicio Nacional de Aduana del Ecuador, se adoptare la medida preventiva de retención provisional se procederá conforme al procedimiento establecido para el efecto por la Directora o el Director General del Servicio Nacional de Aduana del Ecuador.

Adicionalmente, si como resultado de los controles efectuados, luego de la retención provisional si se determinare el cometimiento de una infracción aduanera tipificada como contrabando o defraudación aduanera, las mercancías objeto de infracción serán aprehendidas y permanecerán bajo la custodia del Servicio Nacional de Aduana del Ecuador hasta la culminación del proceso pertinente, esto es, que se hubieren cumplido todas las formalidades aduaneras que correspondan según los procedimientos que para el efecto establezca la Dirección General del Servicio Nacional de Aduana del Ecuador, satisfecho to- dos los tributos al comercio exterior y pagado o garantizada la multa respectiva. En caso que se determinare el cometimiento de una infracción aduanera tipificada como contravención o falta reglamentaria, se procederá de acuerdo con el procedimiento establecido para el efecto por la Dirección General, no obstante las mercancías objeto de infracción deberán ser entregadas una vez satisfechos los tributos al comercio exterior, sin perjuicio del procedimiento sancionatorio iniciado para tal efecto.

La devolución de las unidades de carga y/o medios de transporte en los casos en que se hubiere aplicado la retención provisional, se efectuó siguiendo el procedimiento establecido para el efecto por la Dirección General del Servicio Nacional de Aduana del Ecuador.

\section{Estadísticas}

\section{Recaudaciones}

La figura 2 evidencia el incremento permanente en el nivel de recaudaciones durante el período analizado, las mismas que entre 2013 y 2014 se elevaron en $1,45 \%$ y para el 2015 crecen en 6,4\%. Para el año 2016 se prevén los efectos de la aplicación de sobretasas arancelarias que han significado una reducción de las importaciones en algunas partidas, por lo que el SENAE estimó un decrecimiento de $1,34 \%$ de las recaudaciones en relación con el año 2015.

Figura 2. Recaudaciones totales 2013 - 2016. En Millones de dólares

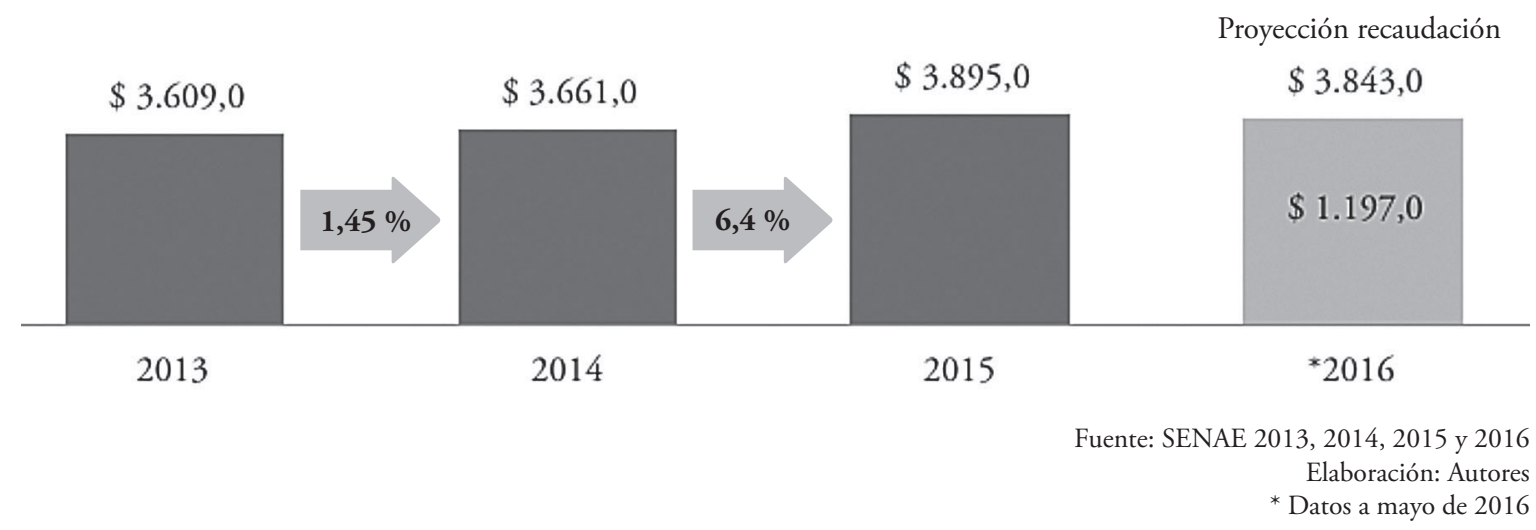




\section{Tiempos de despacho}

En cuanto a los resultados de los tiempos en el proceso de nacionalización de las mercancías, desde la llegada del medio de transporte hasta su salida del depósito, a diciembre de 2007 un importador tardaba un promedio de 11,47 días en nacionalizar la carga; a diciembre de 2015 el tiempo se redujo a 5,04 días, es decir un $56 \%$ menos.

FiguRA 3. TIEMPOS PROMEDIO DE NACIONALIZACIÓN

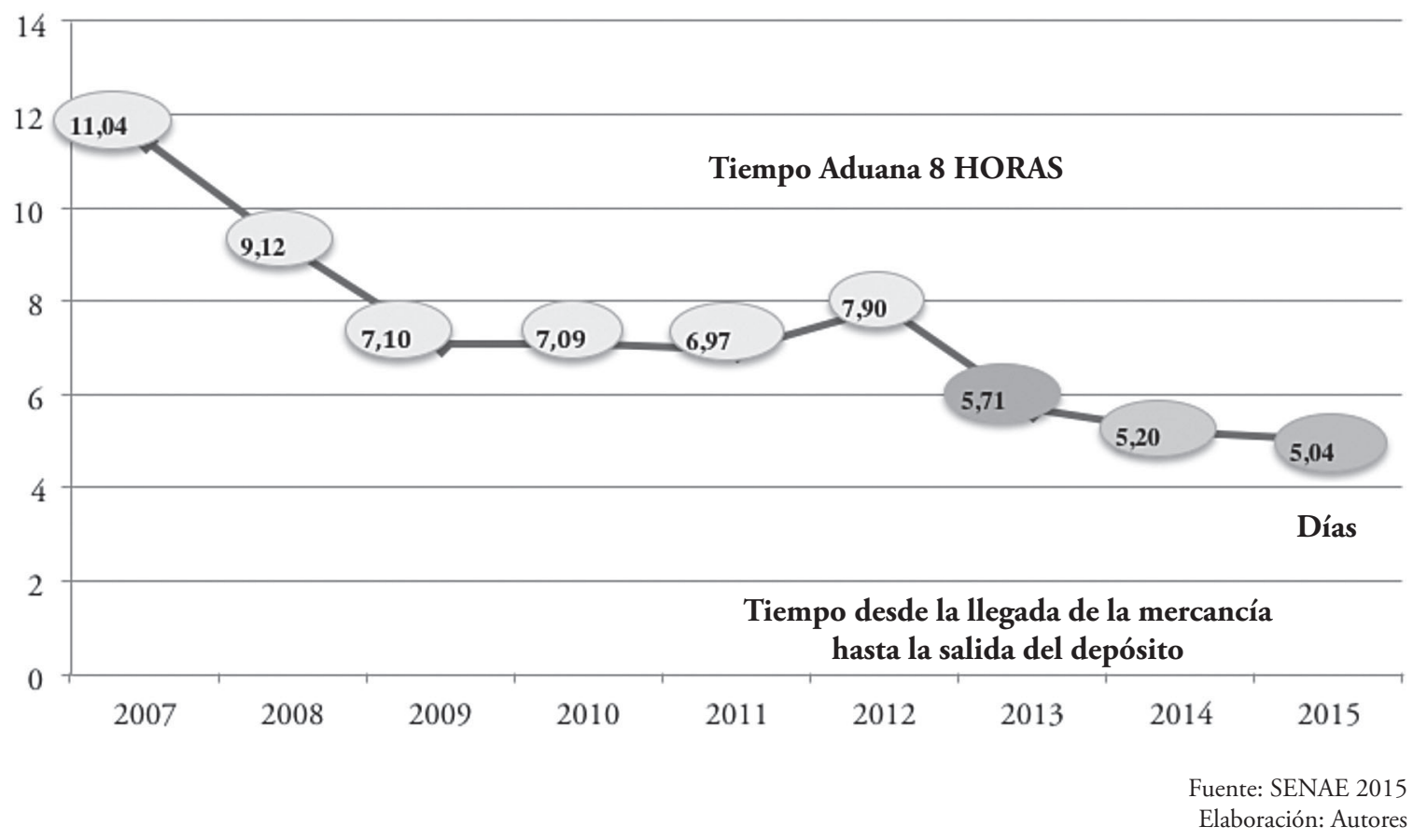

\section{Gestión de Riesgo}

El uso de Gestión de Riesgo para fines de control aduanero permitió a la aduana aplicar criterios de selección que facilitaron obtener información de manera confiable y oportuna para así tomar acciones inmediatas frente a hechos detectados.

\section{Control concurrente}

La gestión de riesgos es un sistema basado en la inteligencia aduanera y está compuesta de actividades que se realizan de forma coordinada para dirigir y controlar el riesgo; el proceso de selección de los trámites para el aforo físico está basado en modelos probabilísticos y determinísticos que se alimentan de las bases de datos y otros criterios que establecen el riesgo de un operador, optimizando los recursos aduaneros en las mer- cancías riesgosas y dando facilidad a las demás. (SENAE, 2015)

En el año 2007, el 66\% de los trámites eran aforados físicamente, constituyendo costos operativos y de eficiencia tanto a la aduana como a los operadores de comercio exterior; el resto de los trámites eran revisados documentalmente. En los años 2013 al 2015, el nivel de aforo físico fue alrededor del 15\%, mientras que el aforo automático bordea el 54\% del total de trámites. Durante el año 2015 se han presentado un total de 3,757 declaraciones, de las cuales 1,480 tienen canal de aforo automático, 1,067 aforo documental y 1,210 aforo físico.

En el primer semestre de 2016, el canal de aforo físico fue alrededor del 14\%, mientras que el aforo automático bordeaba el 56\% del total de trámites. 
Figura 4. CANALES DE AFORO aUtomático y FÍsico INTRUSivo

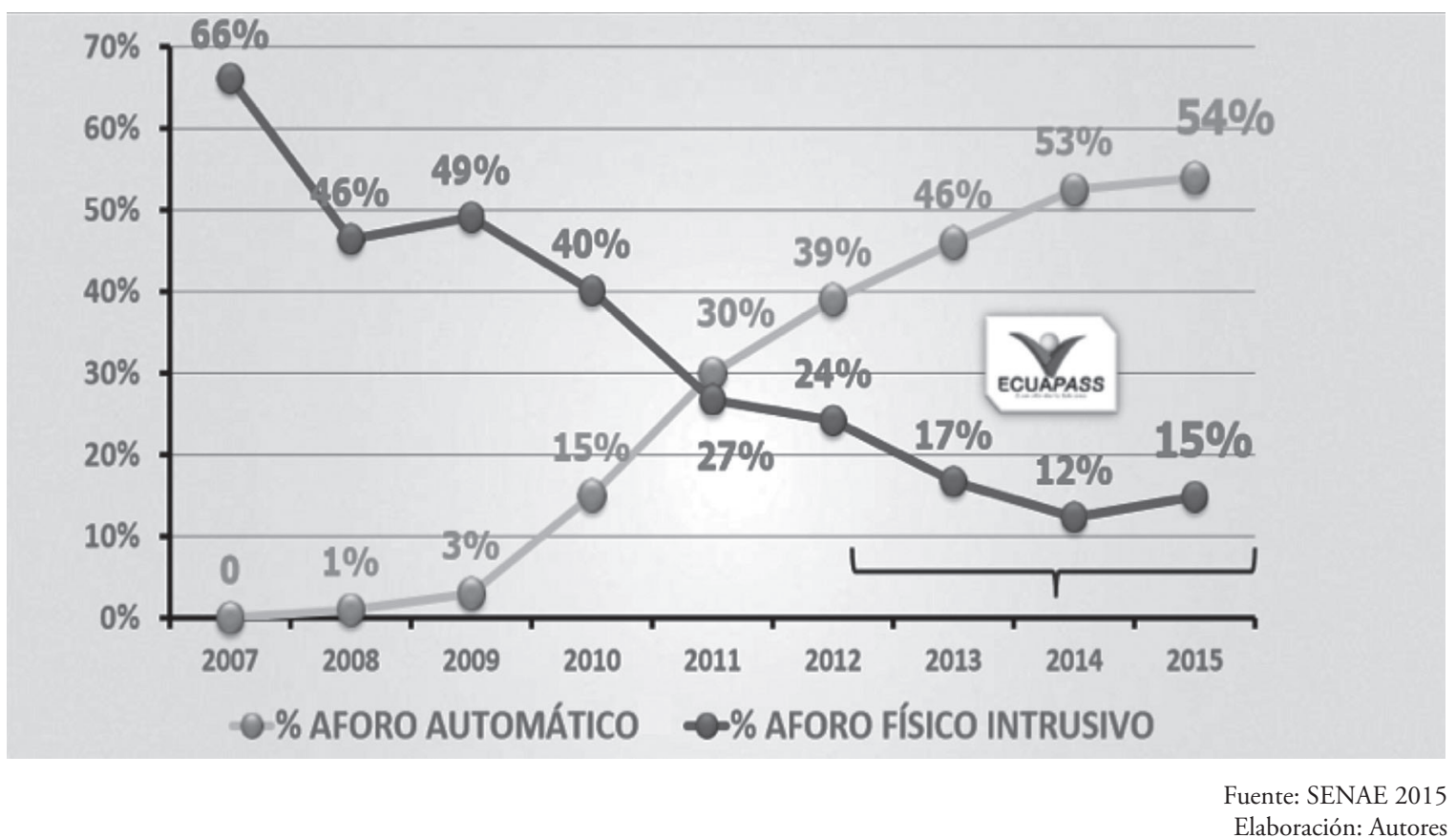

\section{Control Posterior}

Las unidades de control posterior aduanero responden a un Plan anual o periódico de control, en donde se establecen los procedimientos para la selección de empresas u operadores de comercio sujetas al control a través del control documental diferido y auditorías.

\section{Auditorías}

Las auditorías son las revisiones documentarias y comerciales de las transacciones efectuadas por el operador de comercio, con la finalidad de verificar el cumplimiento de las obligaciones aduaneras. Las inspecciones a usuarios de comercio exterior, se refieren al control que debe realizarse a los operadores de comercio exterior autorizados por la Administración Aduanera. En el 2014, de las 54 auditorías practicadas, el valor a cobrar por el SENAE asciende a US\$22'409.046,58, y para el 2015 de las 56 auditorías se determinó US\$ $28^{\prime} 854.863,65$ a recaudar.

Como resultado del control posterior, por concepto de rectificación de tributos, en el 2013 el SENAE determinó el valor a cobrar superior a los 23 millones de dólares, cifra que se ha incrementado año a año como resultado de las auditorías a empresas, la revisión pasiva de las declaraciones aduaneras y a los operadores de comercio exterior en general. 
Tabla 1. Auditorías 2014

\begin{tabular}{l|c|c|c|c|c}
\hline \multicolumn{1}{c|}{ Monto } & $\begin{array}{c}\text { Cantidad } \\
\text { auditorías }\end{array}$ & $\begin{array}{c}\text { Tributos } \\
\text { rectificados }\end{array}$ & Recargo 20\% & Salv. & Total a pagar \\
\hline Subvaloración & 36 & $10.866 .644,78$ & $2.173 .328,79$ & $2.271 .825,64$ & $15.311 .798,57$ \\
\hline $\begin{array}{l}\text { Error en } \\
\text { clasificación }\end{array}$ & 10 & $5.392 .070,78$ & $1.078 .414,15$ & $3.863,17$ & $6.474 .348,10$ \\
\hline $\begin{array}{l}\text { Mal uso de } \\
\text { régimen especial }\end{array}$ & 1 & $84.514,25$ & $16.902,85$ & 0,00 & $101.417,10$ \\
\hline $\begin{array}{l}\text { Error en solc. } \\
\text { dev. de imp. }\end{array}$ & 5 & $433.853,84$ & $86.770,77$ & 0,00 & $520.624,61$ \\
\hline $\begin{array}{l}\text { Mercancía no } \\
\text { declarada }\end{array}$ & 1 & 715,17 & 143,03 & 0,00 & 858,20 \\
\hline \begin{tabular}{l} 
Totales \\
\hline
\end{tabular} & 53 & $16.777 .798,82$ & $3.355 .559,59$ & $2.275 .688,81$ & 22.409.046,58 \\
\hline & & & & & Fuente: SENAE 2014 \\
Elaboración: Autores
\end{tabular}

Tabla 2. Auditorías 2015

\begin{tabular}{l|c|c|c|c|c}
\hline \multicolumn{1}{c|}{ Monto } & $\begin{array}{c}\text { Cantidad } \\
\text { auditorías }\end{array}$ & $\begin{array}{c}\text { Tributos } \\
\text { rectificados }\end{array}$ & Recargo 20\% & Salv. & Total a pagar \\
\hline Subvaloración & 25 & $11.061 .385,51$ & $2.212 .276,73$ & $954.855,03$ & $14.228 .517,27$ \\
\hline $\begin{array}{l}\text { Error en } \\
\text { clasificación }\end{array}$ & 27 & $9.086 .965,80$ & $1.817 .725,32$ & $3.665 .539,32$ & $14.570 .230,44$ \\
\hline $\begin{array}{l}\text { Mal uso de } \\
\text { régimen especial }\end{array}$ & 1 & $39.195,48$ & $7.839,10$ & 0,00 & $47.034,58$ \\
\hline $\begin{array}{l}\text { Error en solc. } \\
\text { dev. de imp. }\end{array}$ & 2 & $2.625,04$ & 525,01 & 0,00 & $3.150,05$ \\
\hline $\begin{array}{l}\text { Mercancía no } \\
\text { declarada }\end{array}$ & 1 & $3.904,58$ & 780,92 & 0,00 & $4.685,50$ \\
\hline Totales & 56 & $20.194 .076,41$ & $4.039 .147,08$ & $4.620 .394,35$ & 28.853.617,84 \\
\hline & & & & & \\
\hline
\end{tabular}


Figura 5. ReCtificaCiones De tributos - VALOR A COBRAR + ReCARGo

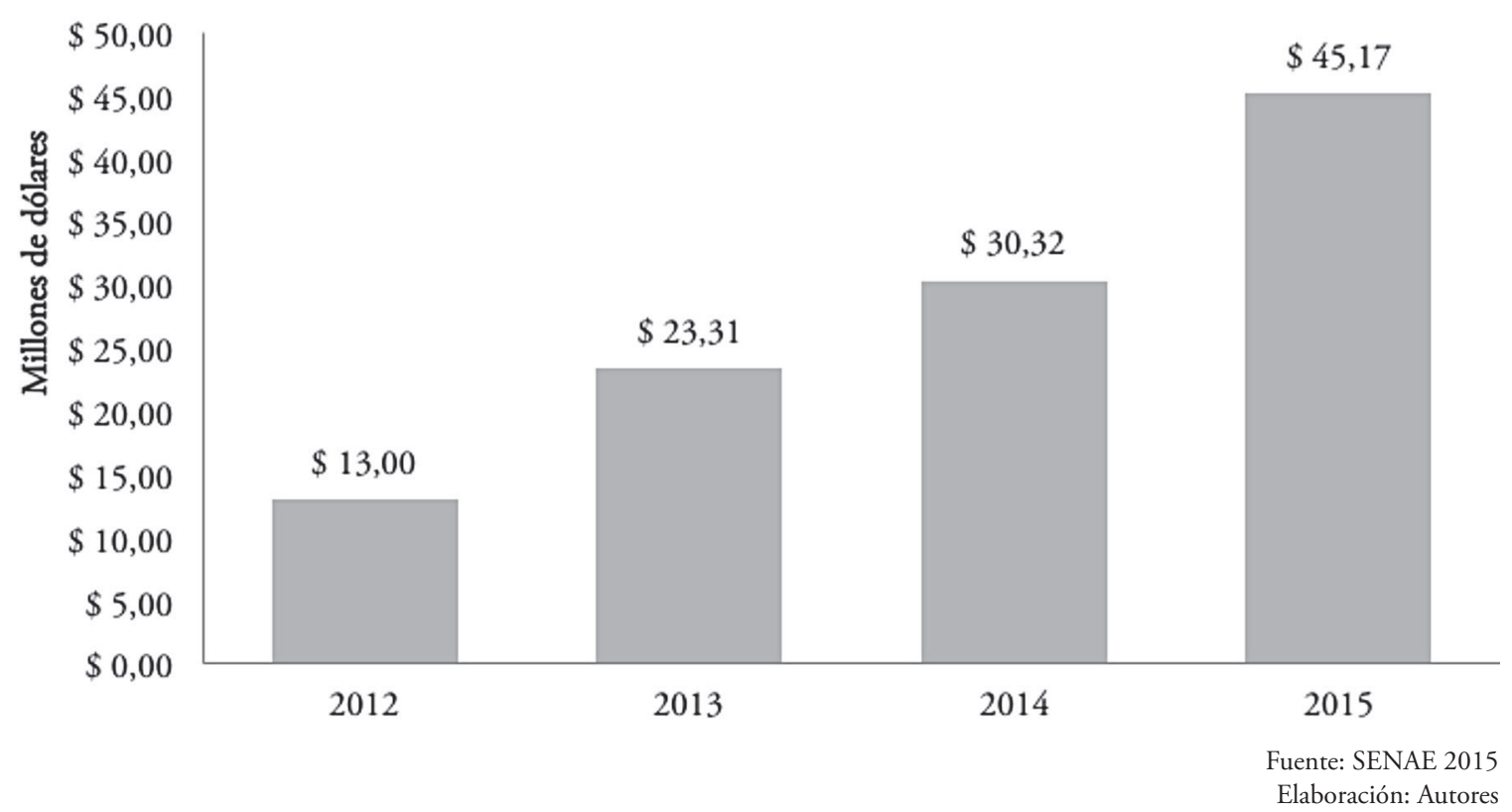

Figura 6. Aprehensiones

EN MILLONES DE DÓLARES

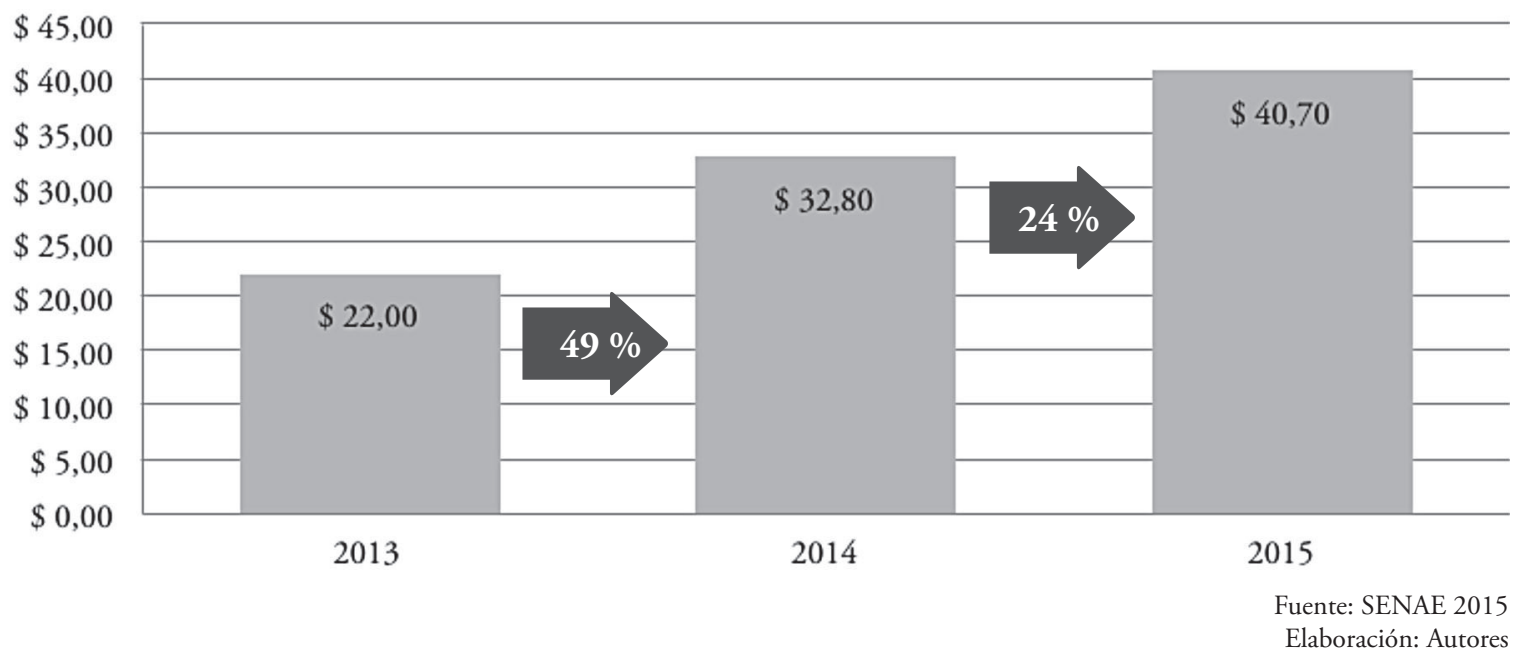

La labor de control que realiza el SENAE a través de la Unidad de Vigilancia Aduanera y la Dirección Nacional de Intervención, presenta resultados en relación con las aprehensiones realizadas que reflejan un incremento constante año tras ańo; esto como efecto de la aplicación de proyectos como el 1-800 DELITO, ECU 911, Operativos combinados con las Fuerzas Armadas y la Policía Nacional, el patrullaje marítimo, el uso de aplicaciones para el control de etiquetas fiscales, entre otros. 
FIGURA 7. APREHENSIONES POR PRODUCTO

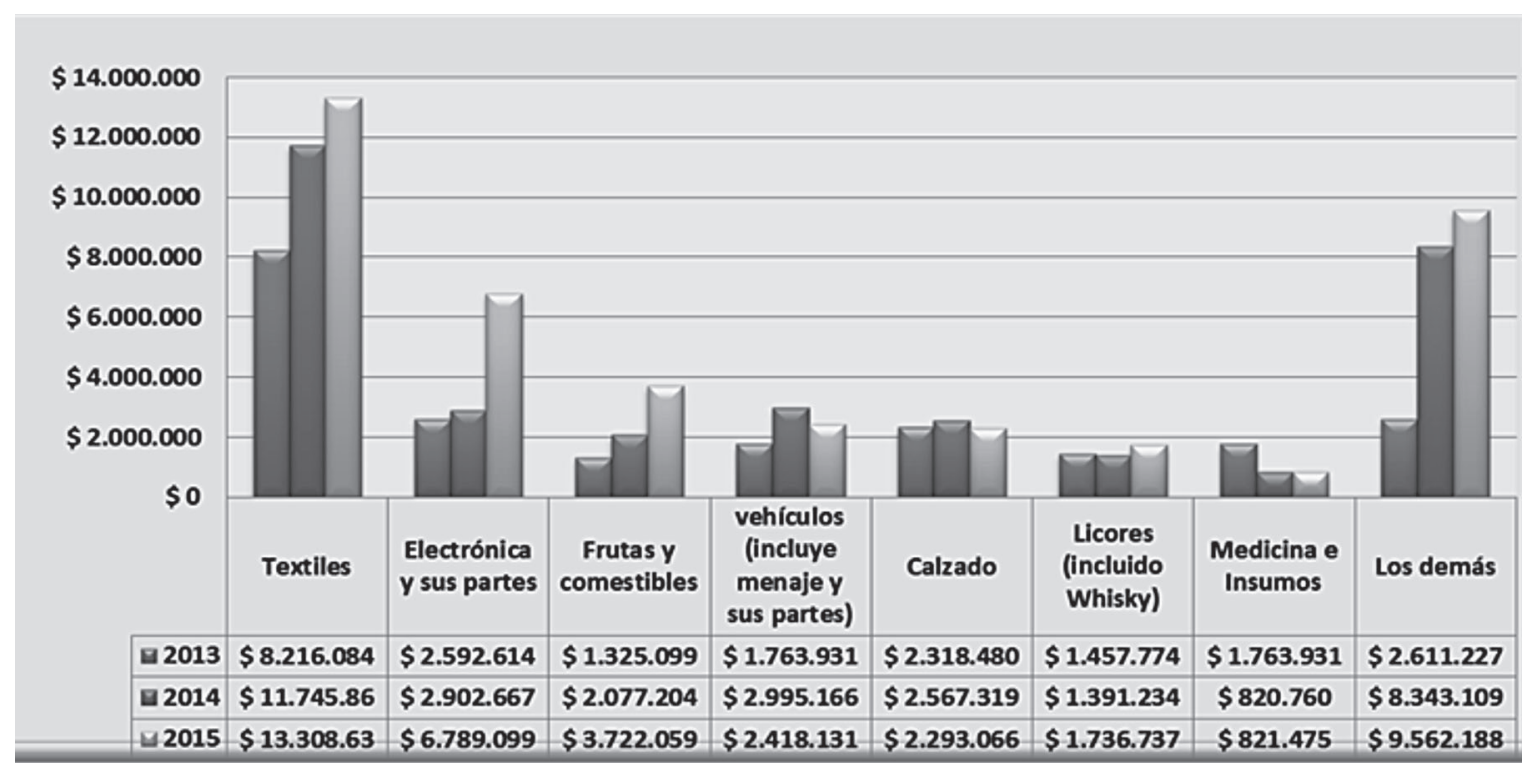

Elaboración: Autores

El gráfico anterior, presenta los productos cuyo ingreso ilegal y/o clandestino tiene mayor incidencia en las aprehensiones realizadas por la Aduana. Los textiles son los productos que más han pretendido evadir el control aduanero, pues en el 2013 la cifra de aprehensiones fue superior los US\$ 8 millones, mientras que en el año 2014 se acercó a los US\$ 12 millones, superando los US\$ 13 millones en el año 2015. Otro producto cuyos montos aprehendidos es particularmente alto son los teléfonos celulares, equipos de computación, televisores a los que se les ha agrupado como Electrónica y sus partes; éstos productos fueron aprehendidos por un valor superior a los US\$2,5 millones en el año 2013 , incrementándose a cerca de US\$ 3 millones en el año 2014, cifra que se eleva drásticamente en el año 2015 en el que alcanza un valor superior a los US\$ 6,7 millones.

Otros productos frecuentemente aprehendidos son: frutas y comestibles, vehículos, calzado, licores, medicinas e insumos, entre otros.

\section{Discusión}

La transformación de las Aduanas, emprendida en los últimos años, ha derivado en un manejo eficiente de la gestión operativa, lo que se refleja en un control aduanero efectivo en sus diferentes fases. El nuevo modelo de gestión de riesgos; el empleo de modelos probabilísticos y determinísticos; la ejecución de operativos de control planificados y coordinados con organismos nacionales e internacionales, ha significado un incremento importante en los resultados del período analizado.

Entre los años 2009 y 2015, las recaudaciones efectivas estuvieron en aumento, notándose un incremento significativo en el año 2013 de US\$ 3.609 millones. Existe una salvedad al comparar las recaudaciones del primer semestre del 2015 con el mismo período en el 2016, en que han disminuido en un $26 \%$, lo que se alinea en las proyecciones del SENAE que espera un decreci- 
miento del $1,33 \%$ para este ańo; las causas estarían dadas por la incorporación de salvaguardias cambiarias a las importaciones de productos provenientes de Perú y Colombia decretada por el gobierno a inicios del año 2015 y que luego en marzo del mismo año la medida fue sustituida por la salvaguardia por balanza de pagos.

Sobre los tiempos en el proceso de nacionalización de las mercancías, desde la llegada del medio de transporte hasta la salida de las mercancías del depósito, a diciembre de 2007 un importador tardaba un promedio de 11,47 días en nacionalizar la carga. A diciembre de 2015, el tiempo se ha reducido en un $56 \%$; es decir, actualmente un importador puede nacionalizar su mercancía en un promedio de 5,04 días, menos de la mitad del tiempo ocupado en el 2007, traduciéndose en abaratamiento de costos de comercio exterior. En este contexto, es preciso aclarar que del total del tiempo de despacho, el 5\% le corresponde a la acción directa de la Aduana, es decir el tiempo transcurrido desde el pago de la liquidación hasta la salida autorizada, el 95\% restante del tiempo de nacionalización, corresponde a las demás etapas a cargo de los diferentes operadores que intervienen directa o indirectamente en el tráfico internacio- nal de mercancías, como: el transportista efectivo, depósito temporal, agente de aduanas, etcétera.

Las mejoras en el manejo de la gestión de riesgos, ha significado la reducción de declaraciones asignadas al canal de aforo físico de un 66\% en el año 2007 al 15\% en el ańo 2015 y en el ańo 2106 se reduce al 14\%; inversamente proporcional a este dato, el aforo automático que en el año 2008 estaba en el 3\% cerró el ańo 2015 con el 55\% y hasta junio del ańo 2106 registra cifras del 56\%.

La tendencia de las Aduanas es fortalecer el control posterior, en ese sentido los resultados que refleja la gestión en el período analizado son, particularmente positivos, pues por el concepto de rectificación de tributos entre el año 2013 y 2015 hay un incremento de prácticamente el cien por ciento. La misma eficacia se observa en cuanto a aprehensiones cuyos valores se duplicaron en el período de estudio, como resultado del empleo de medios tecnológicos para el control como cámaras de seguridad, máquinas de rayos $\mathrm{X}$, sistemas de rastreo satelital, aplicaciones para dispositivos electrónicos, a lo que se suma la constante preparación y desarrollo profesional del personal que es parte del SENAE.

\section{Referencias bibliográficas}

- Asamblea Nacional 1. (29 de diciembre de 2010). Código Orgánico de la Producción, Comercio e Inversiones. Registro Oficial 351. Quito, Pichincha, Ecuador: Editora Nacional.

- Asamblea Nacional 2. (19 de mayo de 2011). Reglamento al Título de la Facilitación Aduanera para el Comercio, del Libro V del Código Orgánico de la Producción, Comercio e Inversiones. Registro Oficial 452. Quito, Pichincha, Ecuador: Editora Nacional.

- CAN 1. (12 de diciembre de 2003). Régimen Andino sobre Control Aduanero. DECISIÓN 574. Lima, Perú: Comunidad Andina.
- CAN 2. (12 de junio de 2000). Asistencia Mutua y Cooperación entre las Administraciones Aduaneras de los Países Miembros de la Comunidad. Decisión 478. Lima, Perú: Secretaría General CAN. Obtenido de <http://intranet. comunidadandina.org/documentos/Gacetas/ Gace571.PDF>

- CAN 3. (15 de diciembre de 2003). Valor en Aduana de las Mercancías Importadas. Decisión 571. Lima, Perú: Secretaría General CAN.

- CAN 4. (2007). Lucha contra el fraude. Lima, Perú: Bellido Ediciones. 
- CEP. (1998). La OMC a su alcance. Quito: Corporación de Estudios y Publicaciones.

- CRAIG, V. (2013). Historia y futuro de la Organización Mundial de Comercio. Ginebra: Publicaciones de la OMC.

- GaraVito, J. A. (2007). Control Aduanero. Lima, Perú: Bellido Ediciones.

- OMA 1. (4 de marzo de 2013). Convenio de Kyoto - Directivas del Anexo General Capitulo 6 - Control Aduanero. Obtenido de Organización Mundial de Aduanas: $<$ http://www.wcoomd.org/en/topics/facilitation/instrument-and-tools/conventions/ pf_revised_kyoto_conv/kyoto_new/ / media/AE00B7CE28BE44CD9408210989EF615C.ashx>

- OMA 2. (4 de marzo de 2013). Convenio de Kyoto - Directivas del Anexo General - Capitulo 7 - Aplicación de la Tecnología de la Información. Obtenido de Organización Mundial de Aduanas: <http://www.wcoomd.org/en/topics/ facilitation/instrument-and-tools/conventions/pf_revised_kyoto_conv/ kyoto_new/ / media/ F 4 CB 7 B CA 02944900A25747558CFF98D2.ashx>

- OMC. (3 de octubre de 2014). Visión general. Obtenido de Organización Mundial del Comer- cio: <https://www.wto.org/spanish/thewto_s/ whatis_s/wto_dg_stat_s.htm>

- SENAE 1. (17 de enero de 2014). Informe de Gestión 2013. Obtenido de Aduana del Ecuador: <http://www.aduana.gob.ec/files/pro/leg/ tra/Informe_Gestion_2013_02.pdf>

- SENAE 2. (29 de abril de 2015). Informe de Gestión 2014. Obtenido de Aduana del Ecuador: <http://www.aduana.gob.ec/files/main/rendicion_cta/2014/2-a-I-InformeGestion2014.pdf>

- SENAE 3. (30 de marzo de 2016). Informe de Gestión 2015. Obtenido de Aduana del Ecuador: <http://www.aduana.gob.ec/files/main/rendicion_cta/2015/2-a-I-InformeGestion2015.pdfs

- SENAE 4. (4 de agosto de 2016). Canal de Aforo Físico. Obtenido de Aduana del Ecuador: <http://www.aduana.gob.ec/contents/popup/ pop_resultados1.jsp>

- SENAE 5. (4 de agosto de 2016). Canal de Aforo Automático. Obtenido de Aduana del Ecuador: <http://www.aduana.gob.ec/contents/popup/ pop_resultados2.jsp>

- SENAE 6. (4 de agosto de 2016). Recaudación y Tiempos. Obtenido de Aduana del Ecuador: <http://www.aduana.gob.ec/contents/popup/ pop_resultados3.jsp> 